\title{
Research on Anti-interference Control of Hydrostatic Guide Rail's Oil Film Thic- kness
}

Wang Youmin, Gong Yifan, Yan Zhichao

School of Mechanical and Automotive Engineering, Anhui Polytechnic University, Wuhu, Anhui 241000, China, E-mail: wymtlf@ahpu.edu.cn, 2190130141@stu.ahpu.edu.cn,2190110110@stu.ahpu.edu.cn

With the rapid development of modern manufacturing technology, people have higher and higher requirements for the quality of mechanical products, and the precision of machine tools for processing mechanical products has gradually increased. Therefore, the development of static pressure guides is particularly important for precision processing industries. The load on the guide rail has an important effect on the thickness of the oil film, and the stability of the oil film thickness directly determines the accuracy of processing. In order to obtain the best control method for the thickness of the oil film, the dimensions of the hydrostatic guide rails and the three-dimensional model of the guide rails were designed and calculated in this paper, and the fuel supply method of the guide rails was determined. The simulation model of the oil film was established and imported from the AMESim software into the FLUENT software to obtain the pressure, velocity, and temperature distribution maps of the oil film. And the pressure distribution data was processed after summarizing. Combined with the relevant mathematical models, the mathematical model of the oil film thickness was finally obtained. Then the Simulink software was used to analyze and the PID control was introduced for comparative analysis. The DOB anti-interference control theory was introduced, and the anti-interference control algorithm was improved. The anti-interference algorithm adapted to the oil film thickness control complete the programming of the modules of the interference controller. The anti-interference control section was created in the Simulink software, and the system of the DOB module was finally completed after packaging. In order to verify the method in $t$ his paper, a static pressure rail test bench was set up, and relevant detection tests were completed. The results of the above studies showed that the control performance was greatly improved after introducing the anti-interference algorithm adapted to the oil film control system.

Keywords: hydrostatic guide, control model-oil film thickness, anti-interference algorithm, simulation, flow field simulation

\section{Introduction}

The oversea ultra-precision machining is more advanced, and the hydrostatic guides is more widely used. A laboratory in the United States has been studying precision machining since the last century and they have successfully developed a DTM-3 diamond ultra-precision machine that can control the processing accuracy at $0.0076 \mu \mathrm{m}$. In the domestic market, the application of hydraulic guides is also growing to be popular. For example, the domestic guide CNC gantry boring and milling machine of model XK2125 is adopting the hydrostatic guide technology. Yet the change of the oil film thickness in the oil chamber of the guide rail would affect the normal operation of the machine tool. Accordingly, optimizing the thickness of the oil film will greatly improve the service life of the table and the accuracy of the processing. Therefore, it is necessary to propose an anti-interference control of the oil film control system. In recent years, more and more researchers have studied the robust control strategy of DOB. Reference [1] described the specific method of DOB control from the angle of anti-interference and performance constraints. Literature [2] analyzed DOB in state space, and analyzed the relationship and difference between state observer and DOB. Literature [3] conducted in-depth analysis on how to perform anti-interference control in non-minimum phase systems. Although the scholars in the above literatures have carried out academic research on DOB control in many directions, they have not applied in the practical, and have only stayed at the theoretical level. After that, a large number of scientific researchers started to put this control method into practice. Reference [4] used anti-interference control to achieve precise control of the servo system; reference [5] used DOB as a torque observer to measure unknown torque and to make online estimates. In summary, although most scholars have begun to solve practical engineering problems, they have not introduced this control method to the design of hydraulic guide rails. Due to the higher requirements on the development of static pressure guide rail control, this paper designed the control system of the hydraulic oil 
circuit, introduced the DOB anti-interference control theory, improved the anti-interference control algorithm, and completed the construction and test of the whole machine. The results showed that the system anti-interference ability was greatly improved and the Oil film thickness stability was the best under the antiinterference control.

\section{Modeling of hydrostatic guideway and design of hydraulic oil supply system}

In order to model the hydrostatic guide rail, the dimensions of each component of the hydrostatic guide rail were designed and calculated [6]; the 3D modeling was conducted by using the UG drawing software; the selection of the hydraulic components was completed and a simulation model for the rail oil supply system was established; the simulation was performed by utilizing AMESim software. Finally, the three-dimensional model of the oil film, the mesh and the boundary conditions were pre-processed, divided and defined respectively through the ICEM CFD software; the divided three-dimensional model was imported into FLUENT for simulation and analysis.

\subsection{D Modeling of Hydrostatic Guides}

The guide rail selected in this article was about 150 $K g$, a carrying capacity of about $450 \mathrm{Kg}$, and a length of about $800 \mathrm{~mm}$, and the width of the guide rail needed to be calculated and determined. The maximum bearing capacity of a guide rail can be determined by Equation 1:

$$
F_{\text {max }}=\frac{F+G}{2}
$$

Where:

$F$...bearing capacity of the guide rail $[N]$,

$G$...dead weight of the guide rail $[N]$.

From the above it can be known that the width of the guide rail was $5.36 \mathrm{~cm}$, rail width of $50 \mathrm{~mm}$ was taken, the length of the guide rail was $800 \mathrm{~mm}$, and the height was tentatively set to $40 \mathrm{~mm}$.
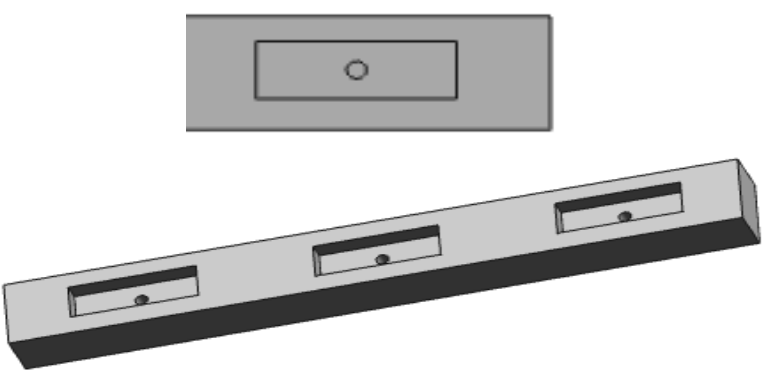

Fig. $13 D$ model of static pressure rail

In this design, the length of the oil chamber of the static pressure guide rail was $125 \mathrm{~mm}$, the depth of the oil chamber was $3 \mathrm{~mm}$, the width of the sealing edge was $12.5 \mathrm{~mm}$, the width was $25 \mathrm{~mm}$, the depth of the oil inlet pipe was $16 \mathrm{~mm}$, and the diameter of the oil port was $5 \mathrm{~mm}$.

Based on the above calculation, a 3D model of the hydrostatic guide rail was established in the UG, as shown in the figure:

\subsection{Design of hydraulic system of static pressure guide rail}

This article chose a constant pressure oil supply system, the design of the specific control principle was shown in the figure below.

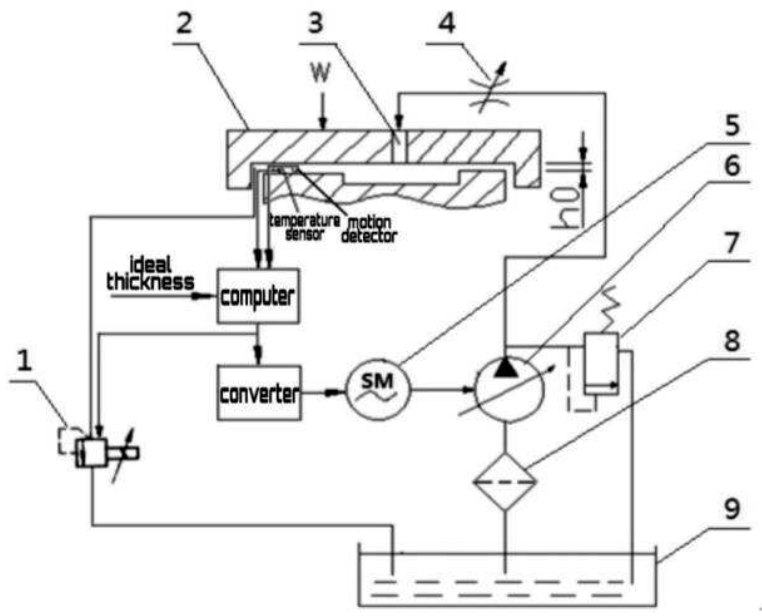

Fig. 2 Oil film thickness control principle of bydrostatic guide rail

In the figure, 1--proportional relief valve, 2--moving rail, 3--oil inlet, 4--throttle valve, 5--AC servo motor, 6--variable pump, 7--relief valve, 8--filter, 9-fuel tank.

As can be seen from the figure: one end of the computer was connected to a converter, which was linked to the AC servo motor 5, the variable pump 6 , the throttle valve 4 and the oil inlet 3 in this order. The oil inlet was arranged on the moving guide rail 2 . The variable pump 6 was connected to the relief valve 7 and the filter 8 . A fuel tank 9 was arranged below the filter 8 , and a proportional relief valve 1 was arranged between the oil tank 9 and the moving guide rail 2 . The system detected the oil pressure and oil temperature of the guide rail through sensors, calculated the control algorithm by the industrial computer, and then obtained the analog signal by signal conversion and power amplification. The signal is used to control the electro-hydraulic proportional relief valve and adjust the electro-hydraulic proportional relief valve Control the pressure, which in turn controled the pressure between the rails.

The selection of components in the hydraulic system was mainly divided into standard and special parts. On the basis of meeting the system requirements, standard parts shall be selected as far as possible to shorten the manufacturing cycle[7]. Various types of selection were listed in Tab. 1 . 
Tab. 1 Selection table of bydraulic components

\begin{tabular}{|c|c|c|}
\hline $\begin{array}{c}\text { Hydraulic Compo- } \\
\text { nents }\end{array}$ & Component Name & Model Parameters \\
\hline Variable & Pressure vane pump & $\begin{array}{c}\text { YBN type, rated pressure } 1.2 \mathrm{MPa} \text {, displacement } 6.8 \\
\mathrm{ml} / \mathrm{r}, \text { allowed maximum speed } 2000 \mathrm{r} / \mathrm{min}, \mathrm{mi}- \\
\text { nimum speed } 600 \mathrm{r} / \mathrm{min}[8]\end{array}$ \\
\hline Motor & $\begin{array}{c}\text { Three-phase asynchronous } \\
\text { motor }\end{array}$ & $\begin{array}{c}\text { Y2-90L-4 type, rated speed } 1400 \mathrm{r} / \mathrm{min}, \text { rated power } \\
1.5 \mathrm{KW}[9]\end{array}$ \\
\hline Filter & Suction filter & WU-16*180 type[10] \\
\hline Relief valve & Direct-acting relief valve & DBDS6G10/25 type \\
\hline tank & & Volume2.2 $L$ \\
\hline
\end{tabular}

\subsection{Simulation of hydraulic system}

As a system simulation software, AMESim was mainly used to model and simulate the system. It can not only perform simulation between the basic component and the control system, but also coordinate with some other simulation software to edit and simulate the same controllable systém [11]. The specific operation steps may include: building a system model, assigning sub-models to components, setting initial parameters, performing simulation and drawing simulation curves, and finally saving and exiting.

The specific setting information of the simulation module was shown in Figure 3.

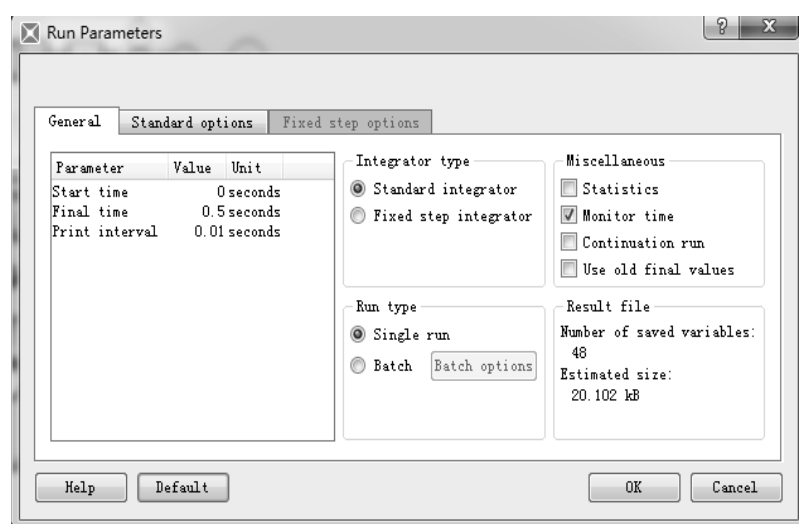

Fig. 3 Simulation mode main window

Start time, end time, time interval, and other parameters were set up, and the values were left at their default values.

\section{Hydraulic pump pressure}

It can be seen from Figure 4 that after the system was added to the load, the pump pressure increased rapidly. When the speed of the hydraulic pump stabilizes at $1400 \mathrm{r} / \mathrm{min}$, the pressure of the pump reaches $0.69 M p a$, and then stabilized at this pressure, which basically meeted the expected design.

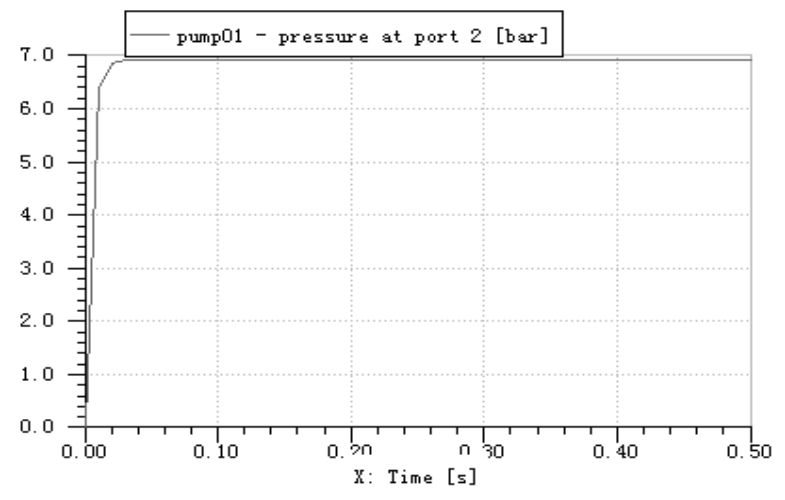

Fig. 4 Pressure diagram of bydraulic pump

Hydrostatic guide rail pressure

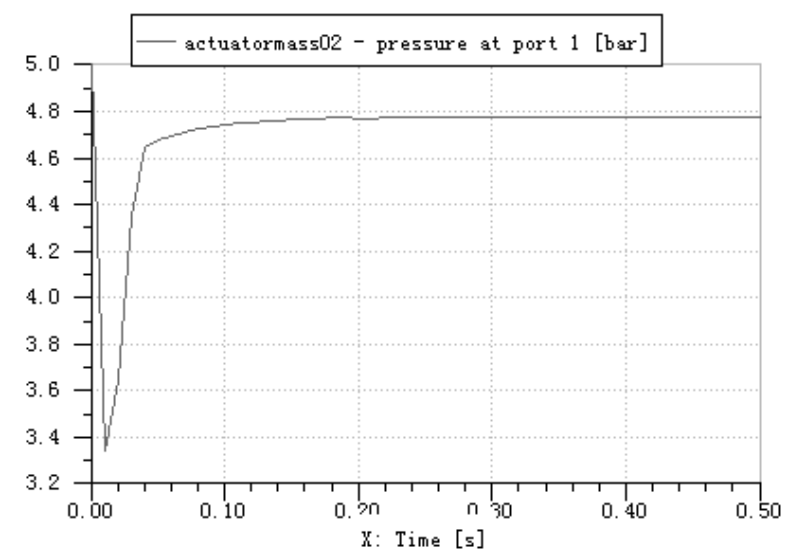

Fig. 5 Pressure chart of static pressure rail

It can be seen from Figure 5 that when the system was just loaded, the total acting force on the hydraulic oil film was very little, and the pressure at the oil inlet was the lowest value. As the load was gradually added, the resistance to the oil film also increased. Similarly, the pressure at the oil inlet increased sharply, but due to the role of the relief valve, the pressure of the guide rail will not always increase. It quickly increased to 0.5 Mpa in a very short time, which was also the calculated 
value of the pressure in the guide rail, and then stabilized at $0.48 \mathrm{Mpa}$, basically in line with expectations.

\subsection{Simulation of the flow field inside the hydrostatic guideway}

For the simulation study of the internal flow field of the open hydrostatic guideway, the calculation and analysis were mainly aimed at the oil cavity. The model structure of the oil film was built by using the Solidworks software, as shown in Figure 6.

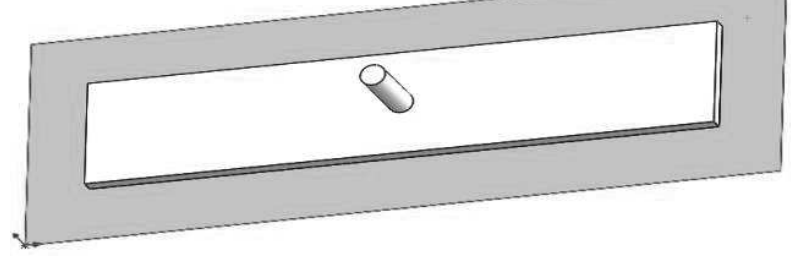

Fig. $63 D$ model of the oil film on the hydrostatic guide rail

This paper used the ANSYS ICEM CFD software to divide the grid and set the boundary. The global parameters of the prism mesh quality were defined and the number of iteration steps was set to 200 steps, then clicked calculate to start the calculation ${ }^{[12]}$. It showed that it had converged at step 115 . Fig.7 was a residual curve diagram during calculation. The convergence of the residual curve determined whether the calculation result was correct. And the convergence of the residual curve was affected by many factors.

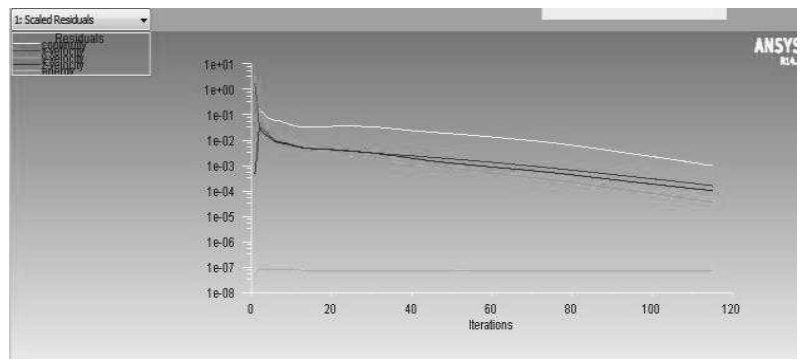

Fig. 7 Residual curve

\subsection{Simulation results analysis}

\section{Oil film pressure distribution diagram}

Figure 8 showed the pressure distribution cloud of the oil film. The pressure distribution cloud diagram can be opened through the software.

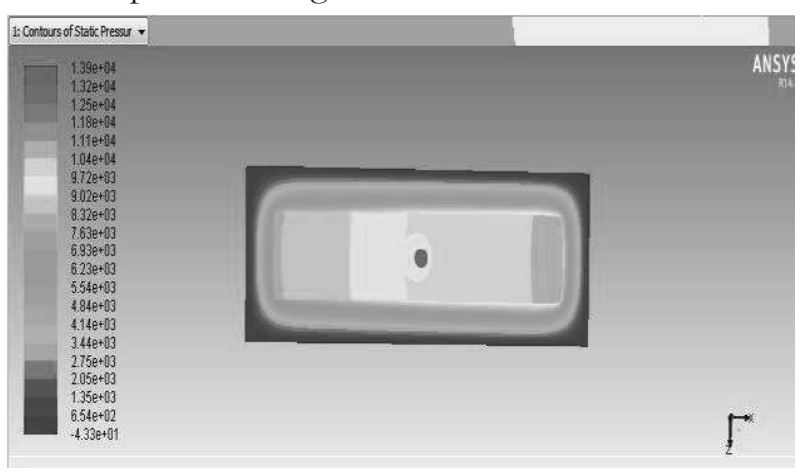

Fig. 8 Cloud diagram of pressure distribution

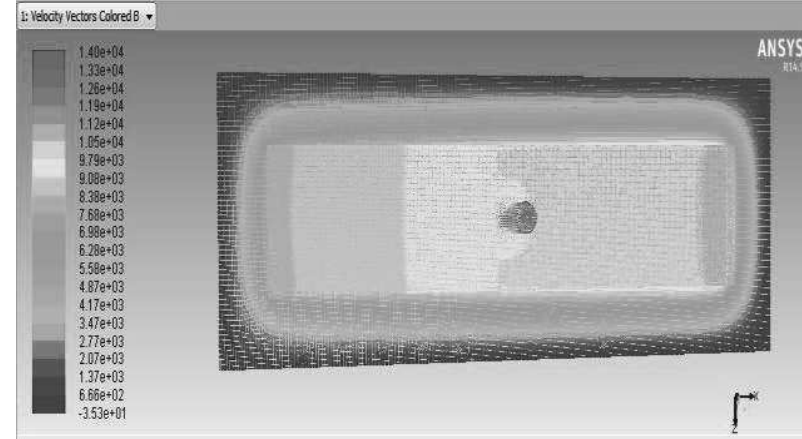

Fig. 9 Vector diagram of pressure distribution

It can be seen from Figures 8 and 9 that the middle region had the highest oil pressure, and it was also the largest load-bearing area. It was basically stable because the outlet pressure was set to 0 , which meeted the requirements. As a whole, the entire pressure field was distributed uniformly and symmetrically with strong regularity. Seen from the figure, the pressure in the oil cavity becomed larger and it basically showed a linear trend, which gradually decreased.

\section{Oil film velocity distribution}

The cloud diagram showing the velocity distribution was shown in Figure 10.

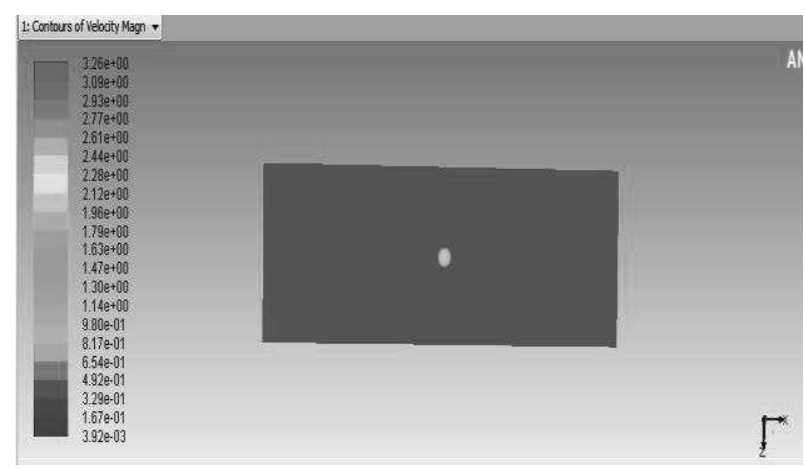

Fig.10 Oil film velocity

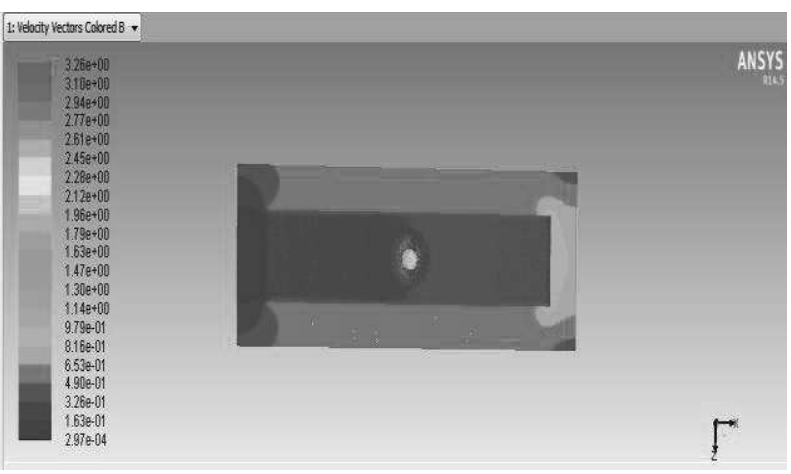

Fig.11 Vector diagram of oil film velocity

The velocity field simulated the state of fluid movement. As shown in Figures 10 and 11, when the guide rail moved at a constant speed, the oil velocity on the right side of the oil film was slightly larger than the left when the oil injection speed and the working speed were superimposed. The flow velocity of the oil 
in the oil chamber was small, and it gradually decreased to zero. The pressure distribution in the basic oil tank was consistent with the actual results.

\section{Oil film temperature distribution}

Through the operation, the hydraulic oil temperature distribution cloud diagram was obtained in Fig.12. It can be seen from the figure that during the movement, the change of the oil temperature was basically maintained at an average state, and only the temperature inside the guide rail was higher. Therefore, when we used hydraulic guide rails, the treatment of the heat dissipation part was also very important. The temperature change will directly affect the processing accuracy.

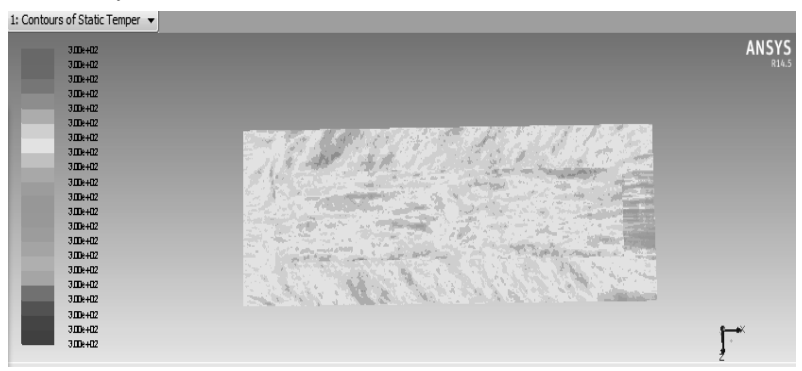

Fig. 12 Cloud diagram of oil film temperature distribution

\section{Modeling of machine tool hydrostatic guide railoil film thickness control}

In order to model the oil film guide, the principle of least squares was used to fit and establish the oil film pressure distribution equation, calculate the total force on the moving rail oil, and derive the control equation of the machine's static pressure guide oil film thickness. For the control model, its stability, controllability and observability were analyzed by using Lyapunov's method, and finally, the model was simulated in MATLAB and optimized in PID.

\subsection{Oil film pressure distribution}

In this part, the least-square method was used to summarize the pressure distribution of the oil cavity, then the integral method was used to find the total force acting on the guide rail, and a more accurate pressure equation was used to establish the control system model[13].

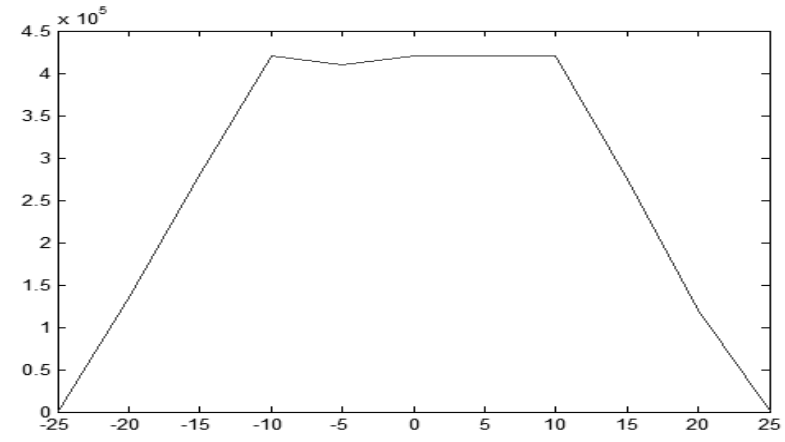

Fig. 13 Oil film pressure distribution
The magnitude of the pressure at each point can be obtained from the simulation of the flow field. Several points were taken for research. The function distribution image was roughly drawn as shown in Figure 13:

It can be seen from Fig.13 that the distribution of the oil film pressure was similar to a quadratic curve, so the highest degree of the fitting function was quadratic. After programing the least squares method by using the MATLAB, the pressure distribution fitting polynomial is:

$$
P=-733 y^{2}-118 y+4.47 e+5
$$

Substituting relevant data for verification, the results were shown in Table 2:

Tab. 2 Verification of pressure curve equation

\begin{tabular}{ccccc}
\hline $\begin{array}{c}\text { Hori- } \\
\text { zontal } \\
\text { coordi- } \\
\text { nate y }\end{array}$ & 0 & 10 & 15 & 20 \\
\hline $\begin{array}{c}\text { Equation } \\
\text { pressure } \\
\text { value } \\
\begin{array}{c}\text { Simula- } \\
\text { tion } \\
\text { pressure } \\
\text { value }\end{array}\end{array}$ & 447000 & 372000 & 280305 & 151440 \\
\hline
\end{tabular}

The results obtained by the pressure fitting equation were basically consistent with the simulated pressure values.

\subsection{Calculation of total oil film action}

A micro-element was taken on the oil film and integrate in the y-axis direction of the guide rail to get the total force acting on the guide rail, as shown in formula 3:

$$
F=2 \int_{0}^{b} p l d y
$$

Where:

$p$...the pressure distribution law of each point of the oil cavity,

$y$...the lateral length of the oil cavity,

$l$.....the total length of the oil cavity.

Substituting into the calculation:

$$
F=2 \times 0.3775 \int_{0}^{0.025}\left(-733 y^{2}-118 y+4.47 e+5\right) d y=8380 \mathrm{~N}
$$

Therefore, the total force of the double guide rail is:

$$
F_{\text {total }}=2 F=2 \times 8380=1.68 \times 10^{4} \mathrm{~N}
$$

3.3 Establishing the mathematical model of the oil film thickness control system

During the model controlling, the core part was to establish a model between the oil and the guide rail. It can be obtained that the relationship between the 
filling flow rate of the rail oil is:

$$
q_{1}=\frac{v_{1}}{\beta_{e}} \cdot \frac{d p}{d t}
$$

Where:

$v_{1} \ldots$ the volume between the moving guide rail and the support guide rail,

$\beta_{e}$..the volume elastic modulus,

$p$...the pressure between the oil and the guide rail.

It can be known from the literature ${ }^{[14]}$ that the relationship between the gap flow caused by the parallel plate flowing is:

$$
q_{2}=\frac{b h^{3}}{12 \mu l} \Delta p
$$

Where:

$b$...the gap width,

$h$...the oil film thickness,

$\mu$..the dynamic viscosity,

$l$....the gap length.

This gave the rail flow equation:

$$
q=\frac{v_{1}}{\beta_{e}} \frac{d p}{d t}+\frac{b h^{3}}{12 \mu l} \Delta p
$$

Where:

$v_{1}$...the gap volume between the moving guide rail and the supporting rail,

$\beta_{e}$..the modulus of bulk elasticity,

$p$...the pressure between the oil and the guide rail,

$b$....the gap width, $h$....the oil film thickness,

$\mu$...the dynamic viscosity,

$l$.....the gap length.

The Taylor series expansion of the above flow equation at the optimal film thickness was obtained:

$$
\begin{aligned}
& \qquad \begin{array}{l}
\Delta q=\frac{v_{1}}{\beta_{e}} \frac{\Delta p}{\Delta t}+\frac{b h_{0}^{3}}{12 \mu l} \Delta p+\frac{b h_{0}^{2} p}{4 \mu l} \Delta h \\
k_{p}=\frac{b h_{0}^{3}}{12 \mu l}, k_{q}=\frac{b h_{0}^{2} p_{0}}{4 \mu l}, \text { we can get: } \\
q=\left(\frac{v_{1}}{\beta_{e}} s+k_{p}\right) P(s)+k_{q} h(s)
\end{array}
\end{aligned}
$$

The moving rail was subjected to four forces in total, and the relationship was:

$$
m \bar{h}(t)=F_{g}-c \dot{h}(t)-k h(t)-F
$$

Where:

$m$...the mass of the moving guide,

$c$.....the damping coefficient,

$k$.....the coefficient of elasticity,

$F$...the total force of the oil on the guide,

$F_{g}$..the gravity.

Use the Laplace to transform the formula 9:

$$
\left(m s^{2}+c s+k\right) h(s)=-\frac{21}{s} p(s)+F_{g}(s)
$$

Substituting formula 10 into formula 8 , through simplification, the mathematical model of the oil film thickness control system can be obtained as follows:

$$
H(s)=\frac{\left(\frac{k_{p}}{2 l}+\frac{v_{1}}{2 l \beta_{e}} s\right) s F_{g}(s)-q}{\frac{m v_{1}}{2 l \beta_{e}} s^{4}+\left(\frac{c v_{1}}{2 l \beta_{e}}+\frac{m k_{p}}{2 l}\right) s^{3}+\left(\frac{c k_{p}}{2 l}+\frac{v_{1} k}{2 l \beta_{e}}\right) s^{2}+\frac{k}{2 l} k_{p} s-k_{q}}
$$

Substituting the empirical value of the parameter into formula 11 can obtain the transfer function of the oil film thickness control system as formula 12 :

$$
H(s)=\frac{0.94 s^{2}+6.56 s-40}{0.14 s^{4}+0.67 s^{3}+0.06 s^{2}-351.56}
$$

State space expressions were composed of state space equations and output equations, which

were used to describe the dynamic behavior of the system. The input-output differential equation

of the control system can be obtained from formula 12 :

\subsection{State space expression of oil film thickness control} system

$$
0.14 y^{(4)}+0.67 y^{(3)}+0.06 y^{(2)}-351.56 y=0.94 u^{(2)}+6.56 u^{(1)}-40 u
$$

Where:

$y$...input signal,

$u$...film thickness.

$$
\dot{x}=A x+B u=\left[\begin{array}{cccc}
0 & 1 & 0 & 0 \\
0 & 0 & 1 & 0 \\
0 & 0 & 0 & 1 \\
-a_{4} & -a_{3} & -a_{2} & -a_{1}
\end{array}\right]+\left[\begin{array}{l}
0 \\
0 \\
0 \\
1
\end{array}\right] u
$$

Due to $m=2<n=4$, the state space corresponding to the differential equation for this input and output was described as:

$y=C x=\left[\begin{array}{llll}b_{2} & b_{1} & b_{0} & 0\end{array}\right] x$

From the previous formula:

$$
a_{1}=4.79, a_{2}=0.47, a_{3}=0, a_{4}=-2511.14, b_{0}=6.71, b_{1}=46.86, b_{2}=-285.71
$$


Substituting into equation 14 , the state space expression of the oil film control system was:

$$
\begin{aligned}
& \dot{x}=A x+B u=\left[\begin{array}{cccc}
0 & 1 & 0 & 0 \\
0 & 0 & 1 & 0 \\
0 & 0 & 0 & 1 \\
2511.14 & 0 & -0.47 & -4.79
\end{array}\right]+\left[\begin{array}{l}
0 \\
0 \\
0 \\
1
\end{array}\right] u \\
& y=C x=\left[\begin{array}{llll}
-285.71 & 46.86 & 6.71 & 0
\end{array}\right] x
\end{aligned}
$$

\subsection{Stability analysis of oil film thickness control sys- tém}

The Lyapunov method can be used to judge the stability of the control system. Stability was a dynamic property of the system, which was specifically described as: the ability of the system to return to a stable state from the disturbed state when the system was disturbed by external conditions[15].

Assume the system's state equation was:

$$
x=A x
$$

Where:

$x$....n dimensional state vector;

$$
\begin{aligned}
& {\left[\begin{array}{cccc}
0 & 0 & 0 & 2511.14 \\
1 & 0 & 0 & 0 \\
0 & 1 & 0 & -0.43 \\
0 & 0 & 1 & -4.79
\end{array}\right]\left[\begin{array}{llll}
P_{11} & P_{12} & P_{13} & P_{14} \\
P_{21} & P_{22} & P_{23} & P_{24} \\
P_{31} & P_{32} & P_{33} & P_{34} \\
P_{41} & P_{42} & P_{43} & P_{44}
\end{array}\right]+\left[\begin{array}{llll}
P_{11} & P_{12} & P_{13} & P_{14} \\
P_{21} & P_{22} & P_{23} & P_{24} \\
P_{31} & P_{32} & P_{33} & P_{34} \\
P_{41} & P_{42} & P_{43} & P_{44}
\end{array}\right]\left[\begin{array}{cccc}
0 & 1 & 0 & 0 \\
0 & 0 & 1 & 0 \\
0 & 0 & 0 & 1 \\
2511.14 & 0 & -0.43 & -4.79
\end{array}\right]} \\
& =\left[\begin{array}{cccc}
-1 & 0 & 0 & 0 \\
0 & -1 & 0 & 0 \\
0 & 0 & -1 & 0 \\
0 & 0 & 0 & -1
\end{array}\right]
\end{aligned}
$$

The solution matrix P can be programmed by the MATLAB software:

$$
P=\left[\begin{array}{llll}
P_{11} & P_{12} & P_{13} & P_{14} \\
P_{21} & P_{22} & P_{23} & P_{24} \\
P_{31} & P_{32} & P_{33} & P_{34} \\
P_{41} & P_{42} & P_{43} & P_{44}
\end{array}\right]=\left[\begin{array}{cccc}
0.1054 & -0.5 & -0.0605 & 0.5 \\
0.5 & 0.0605 & -0.5 & -262.1827 \\
-0.0605 & -0.5 & 262.1827 & -0.5 \\
0.5 & -262.1827 & -0.5 & 262.2724
\end{array}\right]
$$

It can be seen that the matrix $\mathrm{P}$ was a positive definite matrix. Therefore, the oil film thickness control system was stable.

\subsection{Simulation of Oil Film Thickness Control Systém}

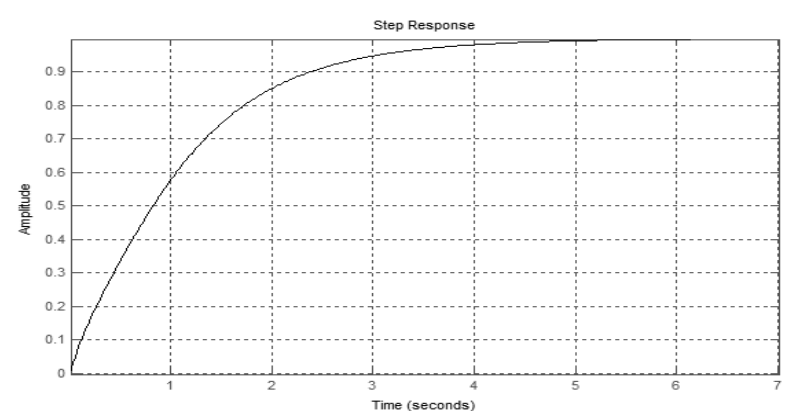

Fig. 14 Step response curve of control system
According to the previous results, the corresponding simulation model was established in Simulink, the step response curve of the oil film thickness control system can be obtained by running the software, which was shown in Fig.14.

In Fig.14 that the control performance is not ideal, and the system stabilizes at about 5.2s, subsequent optimization is still needed.

\subsection{Classic PID control of oil film thickness control systém}

Combining with the function of the simulation module in Simulink, the PID model of the oil film thickness control system was obtained, as shown in Fig.15. 


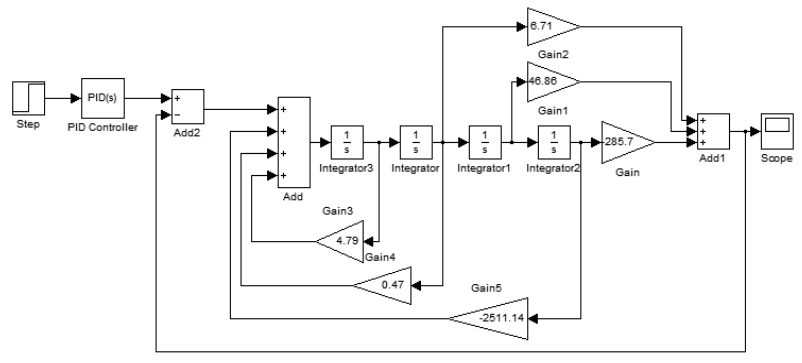

Fig. 15 PID control model of oil film thickness control system

After repeating debugging the parameters of $K_{P}$, $K_{i}$ and $K_{D}$, we finally determined that $K_{P}=22.5$, $K_{i}=60, K_{D}=0$. Where, $K_{P}, K_{i}$ and $K_{D}$ respectively represent proportional gain, integral time constant and differential time constant.

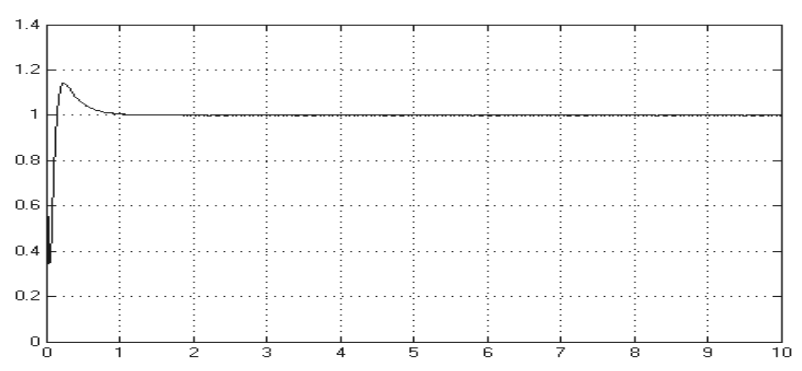

Fig. 16 Step response curve of PID control model of oil film thickness control system

As can be seen from Figure 16, the performance of the control system under PID control has been greatly improved. When the step signal was input, the system stabilized at about 1.1 seconds, but also accompanied by a certain amount of overshoot, thus the subsequent optimization will still be needed.

\section{Anti-interference control of oil film thic- kness control system based on DOB}

DOB (Disturbance Observe) is an anti-interference observer that can be used to help solve the mo-

del mismatch problem in the system. Its basic principle is to obtain the interference by the designed observer, then use this interference as a basis to minimize the impact, and use the front feedback device and the feedback controller in combination. This method was first proposed by Japanese scholar Nakao and others in $1987^{[16]}$, and in the early DOB theory, it mainly used the transfer function as a tool, and the primary research object was SISO system in the frequency domain ${ }^{[17]}$. Nowadays, DOB control has gradually been widely used, such as in the design of motion control systems, electromechanical control, industrial process control and so on.

\subsection{Theoretical analysis of anti-interference control based on DOB}

The basic working principle of DOB is as follows:

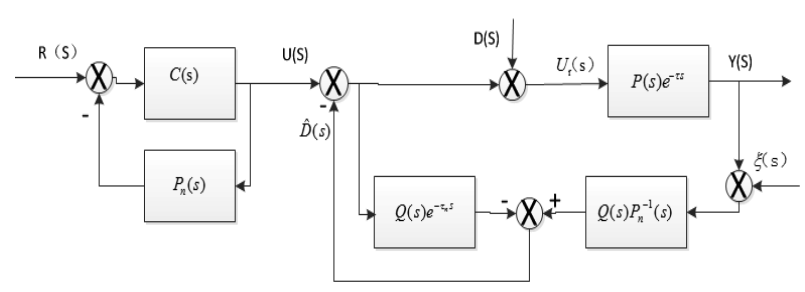

Fig. 17 Block diagram of the DOB control system

From Fig.17, it can be obtained that: $r(t), y(t), d(t), \xi(t) \& \hat{d}(t)$--reference input value, target output value, external interference, observer noise and observer output interference value; $R(\mathrm{~s}), Y(s), D(s), \xi(s) \& \widehat{D}(s)$--Laplace transform value of the signal; $P(s), P_{n}(s)$--controlled object and nominal model; $\tau \& \tau_{n}$--delay in the system and standards.

Design of DOB control system for liquid static pressure guide rail's oil film thickness

Assuming the control system parameters are set as above, we can get the transfer function of the DOB part:

$$
Y(s)=G_{y u}(s) U(s)+G_{y d}(s) D(s)-G_{y \xi}(s) \xi(s)
$$

Where:

$$
\begin{aligned}
& G_{y u}(s)=\frac{P(s) e^{-\tau s}}{1+P_{n}^{-1} P(s) Q(s) e^{-\tau s}-Q(s) e^{-\tau_{n} s}} \\
& G_{y d}(s)=\frac{P(s) e^{-\tau s}\left(1-Q(s) e^{-\tau_{n} s}\right)}{1+P_{n}^{-1}(s) P(s) Q(s) e^{-\tau s}-Q(s) e^{-\tau_{n} s}} \\
& G_{y \xi}(s)=\frac{P_{n}^{-1}(s) P(s) Q(s) e^{-\tau s}}{1+P_{n}^{-1} P(s) Q(s) e^{-\tau s}-Q(s) e^{-\tau_{n} s}}
\end{aligned}
$$

Analysis of steady state performance of DOB control systém

The control target in Fig.17 was a standard equation after compensation, and the following holded:

$$
\lim _{\mathrm{t} \rightarrow \infty} y(t)=\lim _{\mathrm{t} \rightarrow \infty} P_{n}(t) u\left(t-\tau_{n}\right)
$$

It is necessary to consider the influence of the input value of the reference point and the external interference on the whole. The final value theorem can be used to derive the effective suppression of the unstable factors in the system by the anti-interference control. Under steady-state conditions, the following holded: 
Therefore:

$$
\lim _{\mathrm{t} \rightarrow \infty} y(t)=\lim _{\mathrm{s} \rightarrow 0} s Y(s)=\lim _{\mathrm{s} \rightarrow 0} s\left(G_{y u}(s) U(s)+G_{y d}(s) D(s)\right)
$$

$$
\left\{\begin{array}{c}
\lim _{s \rightarrow 0} s Y(s)=\lim _{s \rightarrow 0} s\left(P_{n}(s) e^{-\tau_{n} s}+E(s)\right) \\
E(s)=\left(1-Q(s) e^{-\tau_{n} s}\right) \frac{\left(P e^{-\tau s}-P_{n} e^{-\tau_{n} s}\right) U(s)+P(s) e^{-\tau s} D(s)}{1+P_{n}^{-1}(s) P(s) Q(s) e^{-\tau s}-Q(s) e^{-\tau_{n} s}}
\end{array}\right.
$$

Where:

$E(s)$...the difference due to the compensation problem in the system.

Assuming that the DC gain of the Q filter was 1, but in fact, the DC gain of the controlled target and the standard equation remained the same and constant value, which can be obtained by the limit algorithm:

$$
\lim _{s \rightarrow 0} s E(s)=\lim _{s \rightarrow 0}\left(1-Q(s) e^{-\tau_{n} s}\right)\left(c_{1} s U(s)+c_{2} s D(s)\right)
$$

Where, $c_{1}$ and $c_{2}$ were fixed values.

\section{Design of the pre-filter}

First, solve the $C(s)$, decompose the nominal model, the formula was as followed:

$$
P_{n}(s)=p_{a}(s) p_{m}(s)
$$

Where, $p_{a}(s)$ also included all zeros of $P_{n}(s)$ in the right half complex plane, then control model can be obtained:

$$
q=\left(p_{m}\right)^{-1}\left\{p_{a}^{-1}\right\} *
$$

Thus, the equation expression can be obtained from the calculation:

$$
C(\mathrm{~s})=\frac{q(s) f(s)}{1-P_{n}(s) q(s) f(s)}
$$

In the formula, $f(s)$ can be defined as:

$$
f(s)=\frac{1}{(\lambda s+1)^{n}}
$$

\subsection{Anti-Interference Controller Programming}

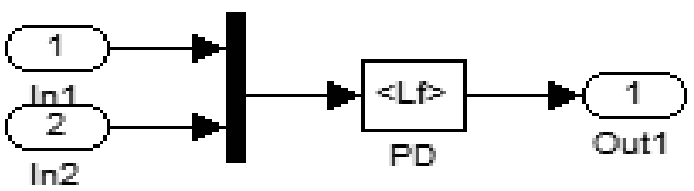

Fig. 18 Modular composition of the feedback controller sub-

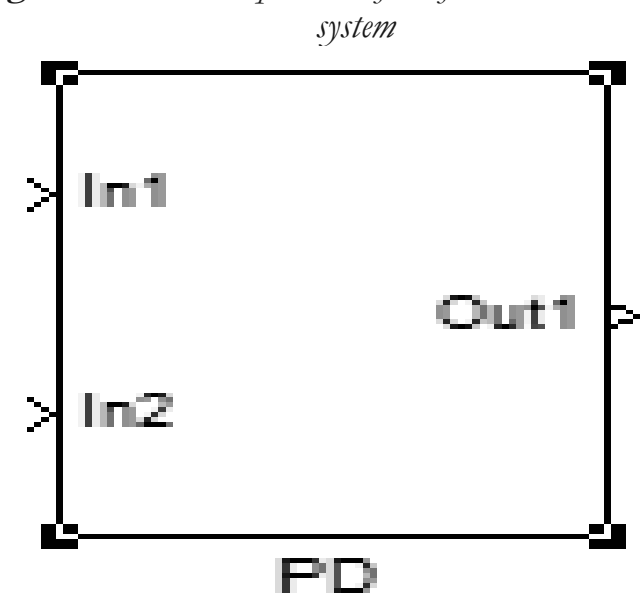

Fig. 19 Feedback controller subsystem
In order to create a subsystem in Simulink, the data input and output of the model were the first thing that needed to be determined ${ }^{[18]}$. Process each part separately in the whole system, and then the target frame can be assembled as a whole.

The modular composition and subsystems of the feedback controller subsystem were shown in Fig.18 and Fig.19 respectively:

The specific settings of the feedback controller subsystem module were: the function name was $P D$; the function parameters were $u$ and ${ }^{v}$; the function module was $P D$; the program added in Edit was the PD. $m_{\text {program [19]. }}$

The subsystem of the feedforward compensator was modular. The structure of the subsystem was shown in Fig.20 and Fig.21.

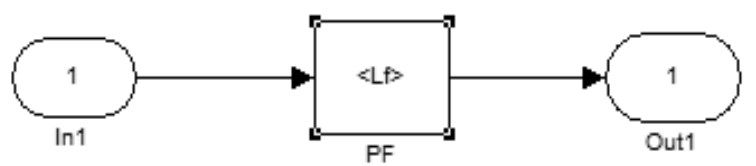

Fig. 20 Modular composition of feedforward compensator subsystem

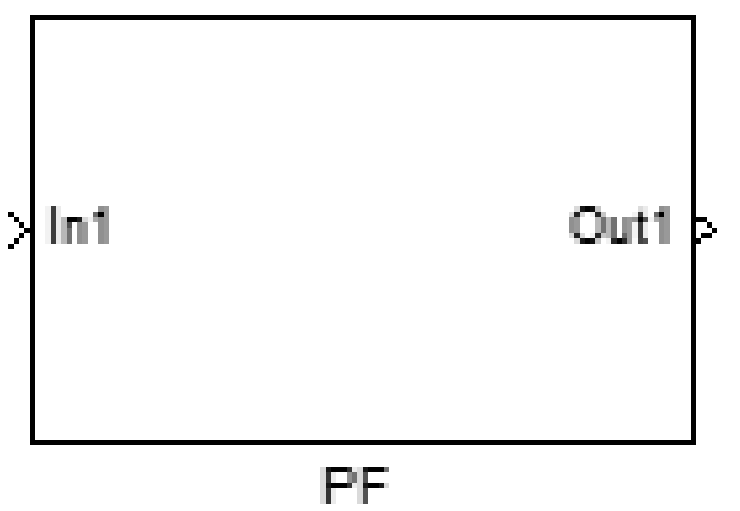

Fig. 21 Feedforward compensator subsystem

The specific settings of the feedforward compensator subsystem module were: the function name was 
$P F$; the function parameters were $f$ and $u 1$; the function module was $P F$; the program added in Edit was the $P F . m$ program.

The subsystem of the disturbance observer was modularly structured. The structure of the subsystem was shown in Fig.22 and Fig.23:

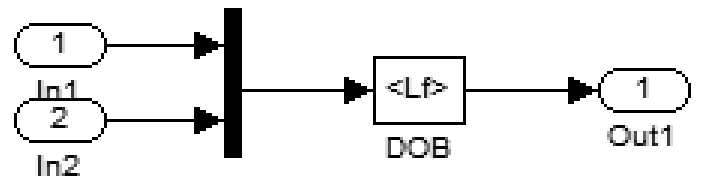

Fig. 22 Modular composition of the disturbance observer subsystem

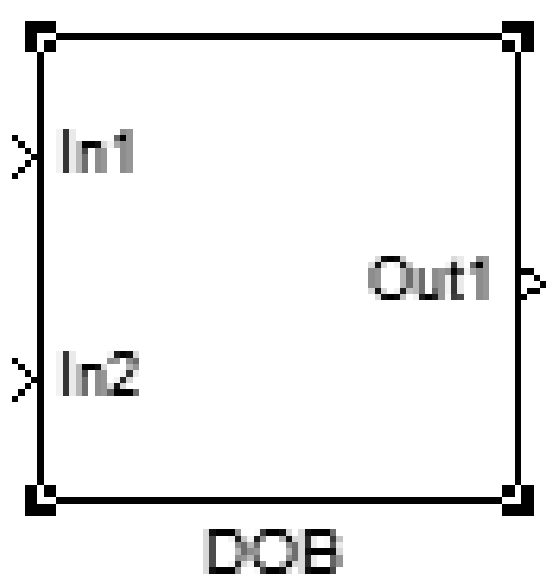

Fig. 23 The disturbance observer subsystem

The specific settings of the interference observer subsystem module were: the controller name was $D O B$; its parameters were set as $d$ and $u 1$; the function module was $D O B$; the program added in Edit was the DOB.m program.

4.3 Anti-interference simulation of hydrostatic guide rail control systém

Assemble each part of the control system from simulink to complete the DOB control system model, as shown in Fig.24.

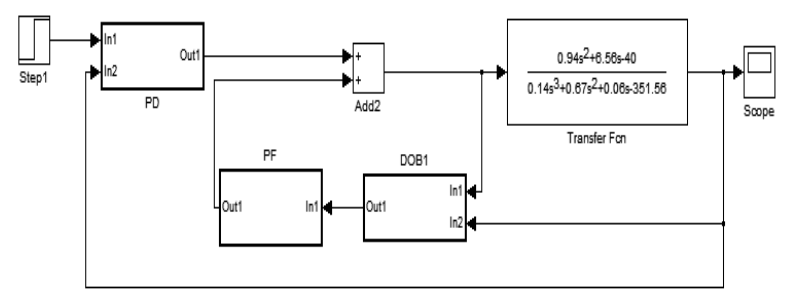

Fig. 24 Anti-interference control model of control system

The step response curve of the anti-jamming control of the control system was obtained by simulink simulation, which as shown in Fig.25.

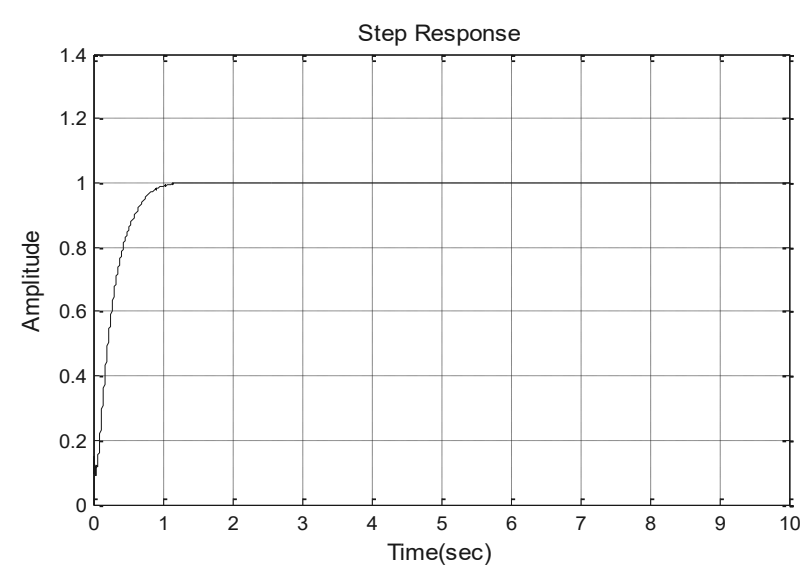

Fig. 25 Step response curve of control system anti-noise control

It can be seen from Fig. 25 that after adding the $D O B$ control, the response speed was greatly improved and with no overshoot occurs. Given an input value, the system stabilized at $0.8 \mathrm{~s}$. Hence the anti-interference algorithm for oil film thickness obtained by improving the anti-interference algorithm in this $\mathrm{pa}$ per was applicable and effective.

\section{Test bench construction and experiments}

\subsection{Construction of test bench}

Test bench device, technical scheme and parameters

This test bench was a hydraulic cylinder-driven type, which adopted the overall structure of a traditional machine tool, and was equipped with a PLC, touch screen and a hydraulic control system[20]. The oil film thickness of the test bench was measured by indirect measurement, the pressure change between oils was converted into oil film thickness by $P L C$. The length, width, and height of the main unit were 1200 $\mathrm{mm}, 800 \mathrm{~mm}$ and $1500 \mathrm{~mm}$ respectively; the length, width, and height of the console were $800 \mathrm{~mm}, 500$ $\mathrm{mm}$ and $1000 \mathrm{~mm}$ respectively; the length of the moving guide was $800 \mathrm{~mm}$, and the left and right strokes were $100 \mathrm{~mm}$ each[21].

\section{Test bench device}

The entire control test device had 6 oil chambers, 3 on each side. The oil entered the moving and static guide rails through the oil chamber to form a layer of oil film, which supported the moving guide rails. Fig.26 showed the reversing hydraulic cylinder of the guide rail that drove the machine tool table. The reversing hydraulic cylinder was shown in Fig.27.

The test bench electrical cabinet was controlled by $P L C$, and the pressure and oil film thickness were detected by $P L C$, and then adjusted. The overall installation of the test bench was completed through the processing and manufacturing of test bench parts and the selection of standard parts. Fig. 28 showed the final assembly of the test bench[22]. 


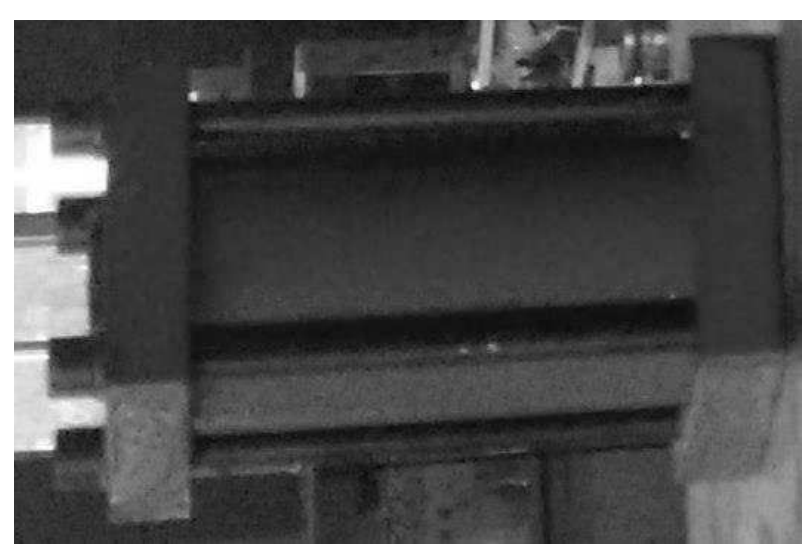

Fig. 26 Hydraulic cylinder loaded on test bench

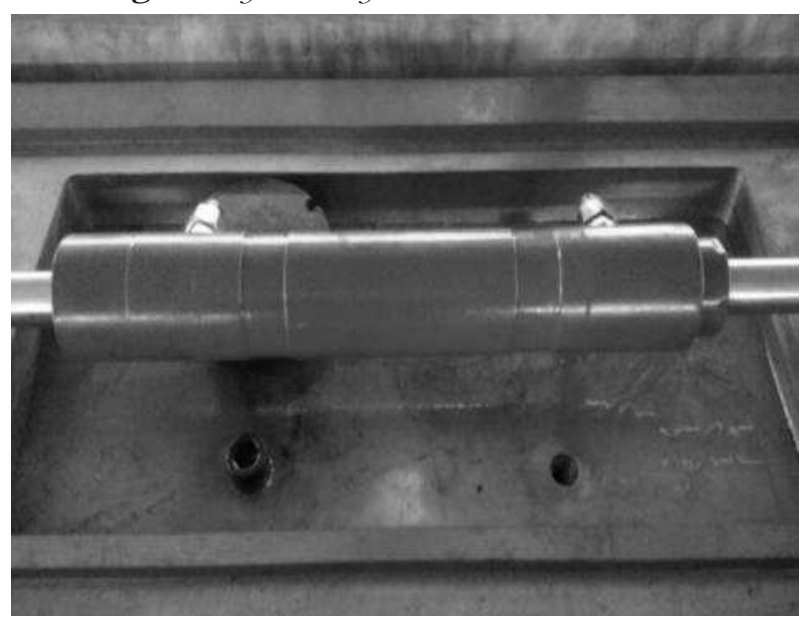

Fig. 27 Hydraulic cylinder

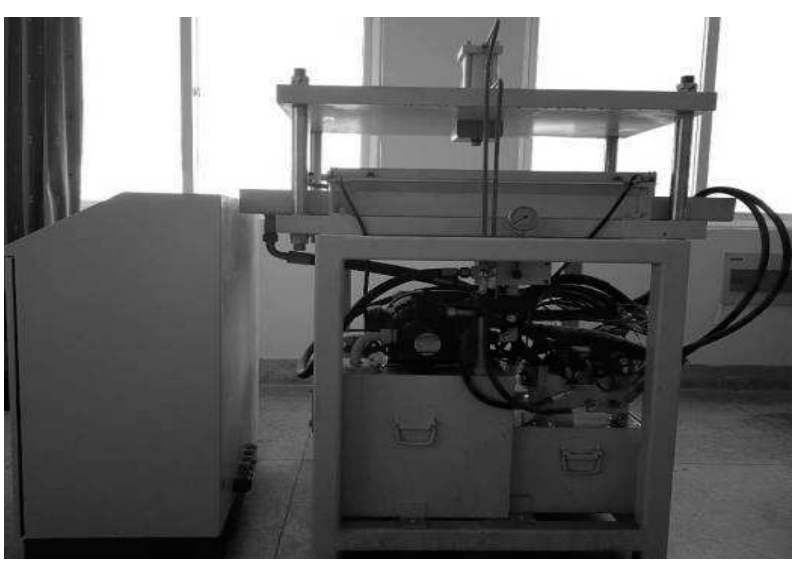

Fig. 28 Assembly drawing of test bench

\subsection{Test machine test}

First, the thickness and stiffness of the oil film were adjusted, and then the load change in the entire process can be controlled by $P L C$. In the test, the $P L C$ was used to control the computer, and the input and receive signals were obtained through the corresponding algorithm to control the signal. The servo valve was adjusted by the signal amplification, and the servo valve adjusted the cylinder to generate the loading force, so that the output force changed with the input signal.

Set different detection points to detect changes in oil film thickness at different positions, and optimize the anti-interference control. The test values obtained were shown in Table 3 below.

Tab. 3 Testing experimental values

\begin{tabular}{cccccccc}
\hline $\begin{array}{c}\text { a input } \\
\text { force(kg) }\end{array}$ & $\begin{array}{c}\text { a input } \\
\text { force(kg) }\end{array}$ & $\begin{array}{c}\text { a display oil } \\
\text { film thic- } \\
\text { kness(um) }\end{array}$ & $\begin{array}{c}\text { a control oil } \\
\text { film thic- } \\
\text { kness(um) }\end{array}$ & $\begin{array}{c}\text { b display oil } \\
\text { film thic- } \\
\text { kness(um) }\end{array}$ & $\begin{array}{c}\text { c display } \\
\text { oil film } \\
\text { thic- } \\
\text { kness(um) }\end{array}$ & $\begin{array}{c}\text { d display oil } \\
\text { film thic- } \\
\text { kness(um) }\end{array}$ & $\begin{array}{c}\text { e display oil } \\
\text { film thic- } \\
\text { kness(um) }\end{array}$ \\
\hline 400 & 403 & 50 & 51 & 53 & 50 & 53 & 52 \\
500 & 497 & 48 & 49 & 46 & 48 & 47 & 48 \\
600 & 603 & 42 & 41 & 42 & 38 & 41 & 40 \\
700 & 700 & 36 & 39 & 35 & 35 & 38 & 36 \\
800 & 799 & 30 & 33 & 30 & 34 & 33 & 32 \\
900 & 902 & 29 & 32 & 28 & 29 & 29 & 30 \\
1000 & 998 & 25 & 31 & 27 & 26 & 23 & 28 \\
\hline
\end{tabular}

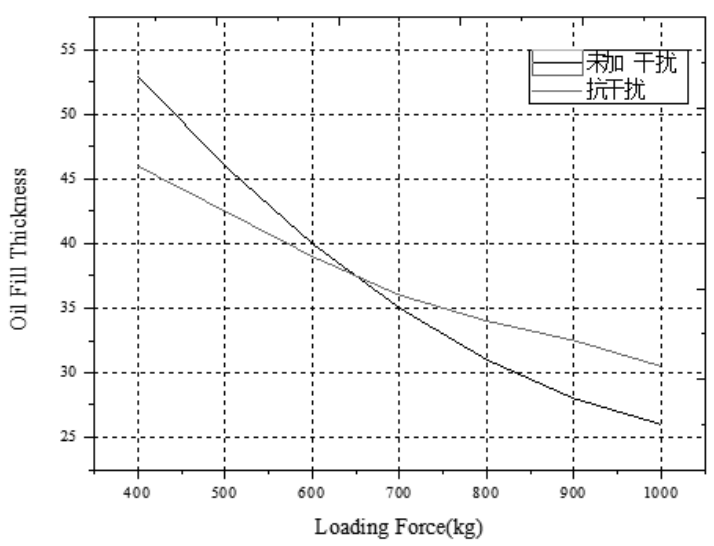

Fig. 29 Variation curve of oil film thickness
By continuously changing the position of the detection point and repeating the test, the corresponding oil film thickness was measured. Fig.29 showed the change of oil film thickness before and after adding anti-interference control.

From the analysis in Figure 29, after adding the DOB anti-interference control, the change of the oil film thickness when the system changed the loading force was much less, so that the oil film thickness of the guide rail was more stable.

\section{Conclusions}

This paper analyzed the flow field distribution of 
the dynamic and static guide rails, and obtained the total force of the oil on the moving guide rails. Based on the flow equation and the force equation of the moving guide rail, an oil film thickness control model for the hydraulic guide rail was proposed. the $D O B$ anti-jamming control theory was introduced, the antijamming control algorithm was improved, an antijamming algorithm suitable for oil film thickness control was developed. Completing the programming of the modules of the interference controller, which greatly improved the control characteristics of the model, highly reduced the transition time and increased the amount of overshoot. The assembly of the rail test bench was completed and the control performance test was performed, the results of which showed that under the anti-interference control, the anti-interference ability of the system was enormously improved, and the oil film thickness stability was optimal.

\section{Acknowledgments}

This article belongs to the major projects of the "Natural Science Foundation of Anhui Province Education Department (KJ2016SD05 and KJ2017ZD12)," the project of the "University Synergy Innovation Program of Anhui Province (GXXT-2019-004)," and the project of the "Teaching Research Project of Anhui Education Department (2019jyxm0229)."

\section{References}

[1] FRANK J. GOFORTH, ZHENG QING, GAO ZHIQIANG. (2012). A novel practical control approach for rate independent hysteretic systems[J]. IS A Transactions, 2012, 51: 477484.

[2] WANG BING-SHU, JIANG PING, LIN YONG-JUN, HAO JING-YU. (2010). Building User-defined Block Library for Activedisturbance-rejection-control Technology in SIMULINKD]. Journal of System Simulation, 2010, 22(03): 610-615.

[3] XIA CHANG-LIANG, LI ZHENG JUN, YANG RONG, QI WEN-YA, XIU JIE. (2005). Controlsystem of Brushless DC Motor Based on Active-Disturbance Rejection Controller[]. Proceedings of the CSEE, 2005, 25(02): 82-86.

[4] GAO QIANG, HOU TUANIONG, QIAN LINDANG, HUANG LEI. (2008). Application of Active Disturbances Rejection Contror in Electro-hydraulic Position Servo System of Pump-controlled Cylinder[]]. Electrical Automation, 2008, 36(08): 121-122.

[5] HAN MINGLI. (2011). Design and FLUENT Analysis on Hydrostatic Guideway of Precision CNC Lathe[D]. Northeastern University, 2011.
[6] LAL BAHADUR PRASAD, BARJEEV TYAGIHARI, OM GUPTA. (2014). Optimal Control of Nonlinear Inverted Pendulum System Using PID Controller and LQR: Performance Analysis Without and With Disturbance Input[]. International Journal of Automation \& Computing, 2014, 11(06): 661-670.

[7] ENBING QI, ZHENYONG FANG, TAO SUN, JIANCHAO CHEN, CHANGZAI LIU, JIAN WANG. (2016). A method for predicting hydrostatic guide error averaging effects based on three-dimensional profile error[]]. Tribology International, 2016, 95.

[8] S. N. SHATOKHIN, S. S. SHATOKHIN. (2014). Closed hydrostatic guides of metalcutting machines[]]. Russian Engineering Research, 2014, 34(5).

[9] ZHANG YANQIN,YU ZEYANG, CHEN YAO, SHAO JUNPENG, YU XIAODONG, JIANG HUI. (2014). Simulation and experimental study on lubrication characteristics of vertical hydrostatic guide rails[]]. High Technology Letters, 2014, 20(03): 315-320.

[10] L. N. BAO, R. B. WU, D. LU, W. Y. WANG. (2016). A novel adaptive anti-interference algorithm based on negative diagonal loading for spoofing and jamming in Global Navigation Satellite System[]. Journal of Communications Technology and Electronics, 2016,61(2).

[11] YOSHINOBU YAMAMOTO, TOMOAKI KUNUGI. (2018). Direct numerical simulation of liquid metal free-surface turbulent flows imposed on wall-normal magnetic field[J]. Fusion Engineering and Design, 2018, 136.

[12] DONGLAI WANG, TIEBING LU, XUESHAN LI, BO CHEN, XUEBAO LI, LI XIE, YONG JU. (2018). Simulation and analysis of human body micro-shocks in the ion flow field near HVDC transmission lines[]]. Journal of Electrostatics, 2018, 93.

[13] XUZHONG SU, XINJIN LIU, XIAOYAN LIU. (2018). Numerical simulation of flow field in the pneumatic compact spinning systems using Finite Element Method[J]. International Journal of Clothing Science and Technology, 2018, 30(3).

[14] MUSTAPHA BOUSSOUFI, AMINA SABEUR-BENDEHINA, M. EL GANAOUI, SOUAD MORSLI, A. OUADHA. (2017). Numerical simulation of the flow field analysis in the mixing twin jets[]. Energy Procedia, 2017, 139.

[15] YU-ZHE QIAN, YONG-CHUN FANG, TONG YANG. (2018). An Energy-based Nonlinear Coupling Control for Offshore 
Ship-mounted Cranes[]]. International Journal of Automation and Computing, 2018, 15(05): 570581.

[16] YONGCHANG YANG, TAO ZHANG, DAN WANG, SHENGWEI TANG. (2019). Investigation of the liquid film thickness in an open-channel falling film micro-reactor by a stereo digital microscopy[]]. Journal of the Taiwan Institute of Chemical Engineers, 2019, 98.

[17] SHILPA TRIPATHI, RAJNARAYAN DE, KOMPALLI D. RAO, SHEIKH M. HAQUE, BHUJAGOUNI K. GOUD, CHILLAKALA PRATHAP, JITENDRA S. MISAL, MANJU M. PATIDAR, VEDACHALAIYER GANESAN, NABA K. SAHOO. (2018). Thickness-dependent optical and structural properties of polytetrafluoroethylene/zinc oxide films by radio frequency magnetron sputtering[]]. Advances in Polymer Technology, 2018, 37(8).

[18] AMEEN M. BASSAM, ALEXANDER B. PHILLIPS, STEPHEN R. TURNOCK, PHILIP A. WILSON. (2019). Experimental testing and simulations of an autonomous, self- propulsion and self-measuring tanker ship model[J]. Ocean Engineering, 2019, 186.

[19] LU EN, LI WEI, YANG XUEFENG, LIU YUFEI. (2018). Anti-disturbance speed control of low-speed high-torque PMSM based on second-order non-singular terminal sliding mode load observer[]]. IS A transactions, 2018.

[20] SHI SHENGLONG. (2018). Design of Hydraulic-Pressure Test-Bed of Hatch Door Switch Device[]. Machinical Engineering\&Automation, 2018(04): 116-117.

[21] HUAICHAO WU, KUNPENG WANG, GUANCHAO SUN, LIMEI ZHAO. (2018). Influence Study of Oil Film Thrust Bearing on Thermal Characteristics of High-speed Precision Roll Grinding Head[J]. Manufacturing Technology, 2018, 18(2): 330-336.

[22] WU HUAI-CHAO, ZHAO LI-MEI, YAN WEN-MENG, XU LEI. (2019). Design and Dynamic Performance Study on Hydrostatic Lubrication System of High-speed Precision Roller Grinding Head[J]. Manufacturing Technology, 2019, 19(6): 959-965. 